\title{
Mindsponge culture: the culture of progress
}

\author{
Minh-Hoang Nguyen \\ Centre for Interdisciplinary Social Research \\ Phenikaa University
}

Yen Nghia, Ha Dong, Hanoi 100803, Vietnam

November 28, 2021

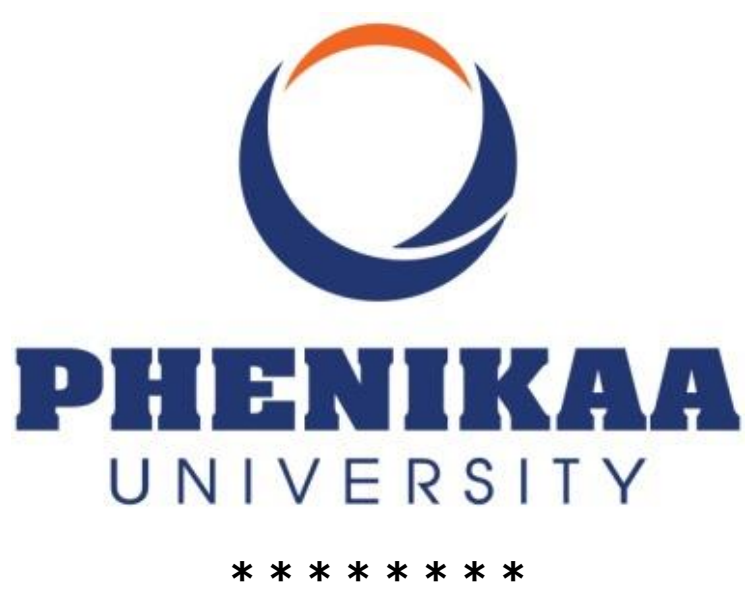

When 2021 ends, it will mark the three-year round of my scientific career. Although the time is short, my scholarly fortune is not small: 38 peer-reviewed articles, two book chapters, and two books. I have always wondered what made me progress so fast in a career that is full of hardship and struggles. Besides the support from my family, friends, colleagues, and my efforts, the Mindsponge culture that I have been learning from my mentor - Dr. Quan-Hoang Vuong - is, perhaps, the most influential factor.

The Mindsponge culture can be defined as a set of thinking processes, beliefs, and behaviors that is result- or target-driven. This culture intertwined closely with my mentor's proposed theoretical frameworks and philosophies [1-7]. It should be noted that the definition of Mindsponge culture here is based on my personal observations, practices, feelings, and imaginations, so other colleagues in the ISR may have different opinions.

Before getting into details, it is necessary to go through the Mindsponge culture briefly. The term "Mindsponge" first appeared as one out of ten measuring dimensions in the i2Metrix, a survey on inclusive corporate innovation capacity, and was defined as the "ability to absorb and integrate new cultural values into corporate mindset toward innovative change and creative performance" [8]. Therefore, Mindsponge culture is actually an entrepreneurship culture in nature. Three fundamental features of 
entrepreneurship (creativity, risk-taking, and open-mindedness) are visible in what I present follows.

\section{As Mindsponge culture is a result- or target-driven culture, how can a person define the target or result they want to achieve?}

There are several ways:

1) choose the target that their intuition tells them to,

2) be receptive to information from the surrounding environment and rationally choose the most beneficial opportunity,

3) listen to seniors who have more experience and wisdom than them.

Either way, choosing the right target to achieve is the most important because it will determine the end product. This target selection is also a Mindsponge informationprocessing process, aiming to maximize the personal perceived benefits and reduce uncertainties based on the existing mindset, information, and insights. Thus, people with different mindsets (or sets of core values) will probably have different priorities and eventually perceive a specific target as more important than others. Nevertheless, our accomplishments will depend on the target that we choose. If we choose a trivial target, our achievement will be limited no matter how talented we are. For this reason, I always tell myself my mentor's saying: "Do the right thing, do thing the right way."

Given my limited knowledge, vision, and wisdom, I usually listen to my mentor to figure out the target or result that I want to accomplish. This method helps me to maximize my expected benefits and reduce uncertainties. My mentor's expectations are very high, so the targets he sets are challenging and often seem impossible to achieve at first. For example, publish papers in Nature's prestigious journals when we have no grants; become an institute ranked second for Economics in Vietnam after five years; publish more than forty high-quality research articles and two books within a difficult 2021 with eight members. After all, I can say those targets are extremely essential to nurture the Mindsponge culture, which needs the hardship to be mastered.

\section{How can a person overcome such hardships?}

It can be done by the target accomplishment process of the Mindsponge culture (see Figure 1). The Mindsponge information-processing processes exist throughout the target accomplishment processes: 1) when determining the target, 2) when obtaining and evaluating information, and 3) when working to achieve the target [9]. To achieve a target, inputs are indispensable. Intuitively, the greater the outcome a person can achieve, the greater amount of input required. However, to apply the Mindsponge culture, it should be kept in mind that cost is irrational due to creative performance.

Creativity can be made through the three principles of the 3D framework: 'out of discipline' thinking, 'within discipline' expertise, and a 'disciplined process' [4]. Here, I 
paraphrased them as within-discipline resources, out-of-discipline resources, and a disciplined process for the sake of interpretation.

- Within-discipline resources are all the resources that an individual owns. They are time, physical and mental capacities, knowledge, skills, and assets.

- Out-of-discipline resources are all the resources that an individual can obtain by looking beyond their boundary or comfort zone. Most of these resources are information, so the more open-minded an individual is, the less limit (or fewer constraints) it faces to achieve new valuable resources.

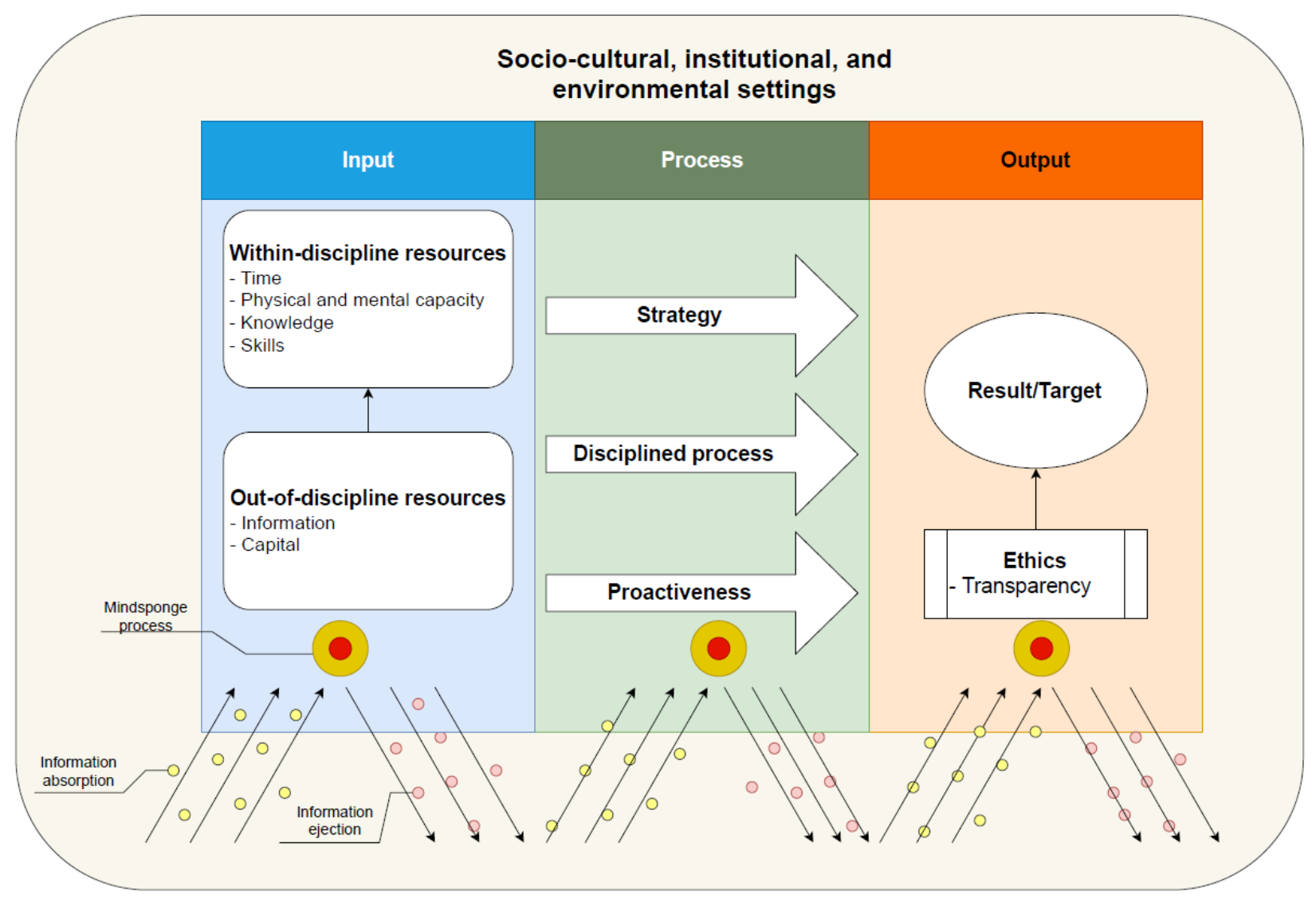

Figure 1: The target accomplishment process of Mindsponge culture

The within-discipline and out-of-discipline resources are the inputs of the output generation process. When they enter the process, they are all treated as information and insights. Such information and insights are evaluated, connected, compared, and imagined by the multi-filtering system of the Mindsponge process to generate the most valuable insights to create a perceived appropriate strategy for achieving the target. The strategy is not always visible, so a disciplined process to continuously optimize withindiscipline resources and connect the most suitable out-of-discipline resources to improve effectiveness and efficiency throughout the process is required. During the process, 
conflicts usually arise when the new information (or new values) contradict the existing values in the mindset (or core values). To determine the optimal information (or value) for achieving the target, the filter has to thoroughly evaluate both information to determine the value to be accepted and rejected, which is costly in time and physical and mental capacity. Therefore, clarifying personal priorities is vital for resource-saving. Sometimes, removing core values (or trusted information) from the mindset for accepting the new ones is required to solve the problem and accomplish the target. This is like giving up the ego, so it is very difficult and, perhaps, mentally painful. However, it can be done if an individual has a "crystal clear" view about their priority. Overcoming the self's ego could save many resources (e.g., time, energy) wasted for the information evaluation process.

Working in a condition full of uncertainty requires me to tolerate risk constantly. To reduce uncertainty towards the target, I have to look for out-of-discipline resources proactively (e.g., through learning new things and skills) and continuously test my thinking while optimizing my existing resources. Doing so is stressful and energetically costly, but it helps me increase the chance of meeting serendipity and generating creative outcomes. When serendipitous and creative outcomes are acquired, the way to the target is shortened, and the rationally calculated cost at the beginning will become irrational. The discoveries of the suicidal ideation mechanism and the Bayesian Mindsponge Framework (BMF) are typical serendipitous outcomes generated when I applied the Mindsponge culture [9-12].

\section{One big question remains. If Mindsponge culture is a result-oriented culture, what is its ethics?}

In my opinion, there are no perfect ethics. We, humans, are living in a world that is interconnected. The "good thing" that we do will almost always inadvertently create adverse impacts on other people or things. For example, we exploit the biosphere for poverty reduction and economic prosperity, but what are the ethics for all the animals we have killed directly and indirectly to achieve those goals? We make war to save lives and bring human rights to other people, but what are the ethics for all the people died because of the war? Even during the COVID-19 pandemic, a vaccination mandate that we believe can save humanities still faces objection worldwide. So, is it ethical to force unvaccinated people to get a vaccine? Or is it ethical to let them do what they want with their body? Apparently, it depends on our perspective, how we see the world, and how we frame the issue to determine ethical or not. In such a complex world, focusing on doing our job and being transparent with what we did seem to be the highest standard of ethics [3].

In sum, the Mindsponge culture is an entrepreneurship culture that urges me to overcome hardship with a transparent mind about my target. Adopting this culture is a tough process, but its fruitful results are worth the cost. Especially in the next decades, humanities have to acquire two crucial targets for sustainable development: curbing 
climate change and reducing biodiversity loss. To accomplish these targets, shifting the eco-deficit mindset to the eco-surplus mindset at the individual level and building ecosurplus culture at the organization level (e.g., business sectors) are required $[13,14]$. Obtaining the Mindsponge culture can help us progress and actualize these objectives through creative performance [15].

\section{References}

1. Vuong QH. (2018). The (ir)rational consideration of the cost of science in transition economies. Nature Human Behaviour, 2(1),5.

2. Vuong QH. (2019). Breaking barriers in publishing demands a proactive attitude. Nature Human Behaviour, 3(10), 1034

3. Vuong QH. (2020). Reform retractions to make them more transparent. Nature, 582(7811), 149.

4. Vuong QH, Napier NK. (2015). Making creativity: the value of multiple filters in the innovation process. International Journal of Transitions and Innovation Systems, 3(4), 294.

5. Vuong QH. (2016). Global mindset as the integration of emerging socio-cultural values through mindsponge processes: A transition economy perspective. In J. Kuada (Ed.), Global Mindsets: Exploration and Perspectives (pp. 123-140). New York: Routledge.

6. Vuong QH, Napier NK. (2015). Acculturation and global mindsponge: An emerging market perspective. International Journal of Intercultural Relations, 49, 354-367.

7. Napier NK, Vuong QH. (2013). Serendipity as a strategic advantage?. In Wilkinson (ed) Strategic Management in the 21st Century (Vol. 1: The Operational Environment), pp. 175-199. Westport, CT: Praeger/ABC-Clio.

8. Vuong QH, Napier NK, Vu KH, Nguyen MC, Tran TD. (2014). Measuring corporate innovation capacity: Experience and implications from i2Metrix implementation in Vietnam. ASEAN Journal of Management and Innovation, 1(1), 1-17.

9. Nguyen $\mathrm{MH}$, Le TT, Nguyen THK, Ho MT, Nguyen TTH, Vuong QH. (2021). Alice in Suicideland: Exploring the suicidal ideation mechanism through the sense of connectedness and help-seeking behaviors. International Journal of Environmental Research and Public Health, 18(7), 3681.

10. Vuong QH, Nguyen MH, Le TT. (2021). A Mindsponge-Based Investigation into the Psycho-Religious Mechanism Behind Suicide Attacks. Warsaw, Poland: De Gruyter / Sciendo.

11. Nguyen MH, Le TT. (2021). Bayesian Mindsponge Framework. Scholarly Community Encyclopedia. Retrieved from: https://encyclopedia.pub/13852

12. Nguyen MH. (2021). From Mindsponge Process to Discovery. OSF Preprints. Retrieved from: https://osf.io/jfnze/ 
13. Vuong QH. (2021). Western monopoly of climate science is creating an eco-deficit culture. Economy, Land \& Climate Insight. Retrieved from: https://elcinsight.org/western-monopoly-of-climate-science-is-creating-an-ecodeficitculture/

14. Vuong QH. (2021). The semiconducting principle of monetary and environmental values exchange. Economics and Business Letters, 9 (3), 284-290.

15. Nguyen MH, Vuong QH. (2021). Evaluation of the Aichi Biodiversity Targets: The international collaboration trilemma in interdisciplinary research. Pacific Conservation Biology, In Press. 